\title{
ARTICLE
}

\section{Testing positive for Human Papillomavirus in routine cervical screening: examination of psychosocial impact}

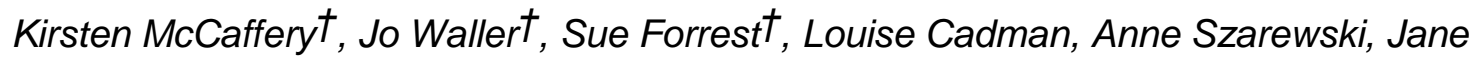 \\ Wardlet
}

tDepartment of Epidemiology \& Public Health, University College London

\section{Address for correspondence:}

Dr Kirsten McCaffery, Screening \& Test Evaluation Program, School of Public Health, University of Sydney, NSW 2006, Australia. Tel: +6129036 9041 Fax: +6129351 5049.

E mail: kirstenm@health.usyd.edu.au

\begin{abstract}
Objective: To examine the psychosocial impact of testing positive for high risk Human Papillomavirus (HPV) among women aged 20-64 $(n=428)$ attending primary cervical screening at a well-woman's clinic in London, UK.

Design: Cross-sectional postal questionnaire survey. Measures were taken at baseline and one week after the receipt of HPV and cytology screening results.

Main outcome measures: Psychosocial and psychosexual outcomes were anxiety, distress and feelings about current, past and future sexual relationships.

Results: Women with normal cytology who tested positive for HPV (HPV $\left.{ }^{+}\right)$were significantly more anxious and distressed than women who were negative (HPV $\left.{ }^{-}\right)$using both a state anxiety measure $(F(1,267)=29, p<.0001)$ and a screening specific measure of psychological distress $(F(1,267)=69, p<.0001)$. Women with an abnormal or unsatisfactory smear result, who tested $\mathrm{HPV}^{+}$were significantly more distressed than $\mathrm{HPV}^{-}$women with the same smear result $(\mathrm{F}(1,267)=8.8, \mathrm{p}=.002)$, but there was no significant difference in state anxiety. Irrespective of cytology result, $\mathrm{HPV}+$ women reported feeling significantly worse about their sexual relationships. Approximately one third of women who tested positive reported feeling worse about past and future sexual relationships compared to less than $2 \%$ of $\mathrm{HPV}^{-}$women.

Conclusion: The findings suggest that testing positive for HPV may have an adverse psychosocial impact, with increased anxiety, distress and concern about sexual relationships. Psychosocial outcomes of HPV testing need further investigation and must be considered alongside clinical and economic decisions to include HPV testing in routine cervical screening.
\end{abstract}

Keywords: Psychosocial impact, HPV testing, Primary cervical screening, Human papillomavirus, Cervical neoplasms 


\section{Introduction}

Each year over 4 million cervical smears are taken in the UK with more than $80 \%$ of women aged 25-64 years participating in routine cervical smear testing at least every 5 years (1). Major developments are taking place in the field which now offer the potential for considerable change to conventional cytological methods of screening for precancerous disease. The development of sensitive tests for high-risk types of the human papillomavirus (HPV) have established HPV infection as the necessary causal agent in cervical cancer (2). The inclusion of testing for HPV DNA in cervical screening either at triage among women with borderline smears or ASC-US (atypical squamous cells of undetermined significance, US terminology), or at primary screening, has received considerable support (3-9). The UK Department of Health, Medical Research Council/ National Health Service and US National Cancer Institute are currently running trials of HPV testing within existing cervical screening programmes (10-12) and HPV testing at triage for women with ASC-US has recently been included within the revised 2001 Bethesda Consensus Guidelines for the management of abnormal cytology and is becoming part of routine care for women in the US (13).

HPV testing may offer a number of advantages to conventional cervical screening, such as increased sensitivity for high grade precancerous disease, the potential to increase screening intervals for HPV negative women, and the reduction of unnecessary colposcopies among women with borderline smears (ASC-US) (14). However, HPV testing has been criticised for its lack of specificity and the potential for large numbers of women to test positive in the absence of

\section{Page 1438 - - >}

clinically significant cytological abnormality $(15 ; 16)$. Importantly, it may also raise critical psychosocial issues among those who participate. As a sexually transmitted infection (STI) HPV may be strongly stigmatised and could therefore cause anxiety and distress among women who test positive. Despite the tremendous interest in HPV there has been little empirical research on the psychosocial implications of testing in routine cervical screening. Several studies have noted that there may be adverse psychosocial consequences (17-20), but the impact of testing positive for high-risk types of HPV has not been quantitatively evaluated among women participating in routine conventional screening for cervical cancer.

Examination of the psychosocial impact of HPV testing is needed to ensure that the benefits outweigh the possible adverse psychosocial consequences particularly when such large numbers of women stand to be affected. Establishing the psychological and social outcomes of any screening test before deciding whether it should be provided is well documented (21) and is a key consideration for any new candidate test for mass screening. This paper presents data on the psychosocial impact of testing positive for high-risk HPV among women participating in a clinical study of HPV DNA testing alongside routine cytological screening in the UK. The results of the clinical study are in preparation and will be published elsewhere. Findings related to knowledge and understanding of HPV have also been examined in this sample (22). 


\section{Participants and procedures}

The study was approved by the University College London Hospitals local research ethics committee. All women gave informed consent to participate in the study.

A total of 428 women attending a National Health Service well-woman clinic in central London for routine conventional cervical screening were recruited into the study. Women were given standard information about HPV and HPV testing developed by a clinical specialist (AS). Information covered the sexually transmitted nature of HPV, its high prevalence, association with cervical intraepithelial neoplasia $(\mathrm{CIN})$ and potential for long periods of latency. The design was a cross-sectional survey using a postal questionnaire. Women completed a baseline questionnaire before screening which included socio-demographic measures, behavioural risk factors (smoking and number of sexual partners) and anxiety, and were given a cervical smear and HPV test (Digene HCII HPV test) by a clinician or clinic nurse. Women were sent their cervical smear and HPV results by post and those who tested HPV positive were sent a second copy of the information leaflet (as described above). A telephone information and support line was available to all women as standard practice through the clinic. Women with borderline or abnormal cytology, unsatisfactory smears, or positive HPV test results, were invited for colposcopy.

A self-report questionnaire was sent to participants one week after they received the test results to assess psychosocial outcomes. All psychosocial measures were taken prior to colposcopic follow-up (which occurred within one month of cervical smear results being given). Anxiety was measured both at baseline and follow-up with the widely used short form of Spielberger's State Trait Anxiety Inventory (STAI) (23). The scale consists of six items assessing current levels of anxiety (score range from 6-24). A second psychological measure, specific to smear testing was also used at follow-up. The wellvalidated Cervical Screening Questionnaire (CSQ (24)) assesses psychological distress following cervical screening. The nine item scale covers perceptions of general and gynaecological health, body image, concerns about fertility, sexual interest, fear of cancer or serious illness, and pessimism. Response options were presented on a four point likert scale, less than usual, same as usual, rather more than usual, much more than usual, for the first four items, and better than usual, same as usual, worse than usual, much worse than usual, for the remaining 5 items (score range from 0-27). Additional measures developed by the authors were used to assess women's feelings towards their current sexual partner,

Page 1438 - - >

previous sexual partners and future sexual relationships, since receiving their HPV test result (shown in Table 3).

Data analysis used 2-way ANOVAs for comparison of means and chi-square tests for comparison of proportions, with 2-sided Fisher's Exact Tests where cells had frequencies $<5$ using SPSS 10 . In the analyses of anxiety and psychological distress (STAI and CSQ), a 2x2 ANOVA was carried out and simple effects were tested to compare groups.

\section{Page $1440-->$}




\section{Results}

In total, $73 \%$ ( $n=311)$ of women returned the follow-up questionnaire. Forty respondents were excluded from the analysis because they had completed the follow-up questionnaire after their colposcopy appointment $(n=28)$, or were part of the small randomly selected control group of women who had a normal smear and a negative HPV result (HPV-) women who were invited and attended for colposcopy $(n=12)$.

We examined socio-demographic, behavioural risk factors, HPV and smear test results between questionnaire responders and non-responders. The only significant difference between the groups was in car ownership, with more responders being car owners than non responders $\left(40 \%\right.$ vs $29 \%, \chi^{2}=3.9$ [1] $\left.p=.047\right)$. We also compared responders excluded from the sample because they had completed their questionnaire after attending for colposcopy, and participants invited for colposcopy included in the study analyses (who completed the questionnaire prior to their colposcopy) with the rest of the sample. Again, no significant differences were observed.

In total, 271 participants were included in the main analyses of psychosocial impact. Participants were predominantly white, aged under 35 years (mean $=32$; sd 8.0; range 20-61 years) and had tertiary education (73\%) (see Table 1). A quarter $(26 \%, n=69)$ of the participants had an HPV positive $\left(\mathrm{HPV}^{+}\right)$result, $9 \%(\mathrm{n}=24)$ had an abnormal cervical smear and $6 \%(n=16)$ had an unsatisfactory smear result (see Table 2$)$. For the subsequent analyses participants were categorised according to their cervical smear result and their HPV test result, as follows:

i) Normal smear, HPV negative $(n=185)$

ii) Normal smear, HPV positive $(n=46)$

iii) Abnormal/unsatisfactory smear, HPV negative $(n=17)$

iv) Abnormal/unsatisfactory smear, HPV positive $(n=23)$.

Women with an unsatisfactory smear result were invited for colposcopy and treated similarly to those with a positive smear result. They had raised levels of anxiety of similar magnitude to the borderline smear group, so for most analyses, they were grouped with women with abnormal cytology. Numbers did not permit analysing them as a separate group, and as they were invited for colposcopy which is well known to cause anxiety, their experience was considered most similar to women with abnormal cytology.

Socio-demographic characteristics and anxiety scores taken pre-screening were examined to check for any baseline differences between the smear and HPV groups, but there were no significant differences.

\section{- Insert Tables 1 and 2 about here -}

\section{Analyses of psychosocial impact}

The first analyses examined state anxiety (STAI) and psychological distress (CSQ) in the four smear/HPV groups listed above. Mean scores with $95 \%$ confidence intervals are shown for each group in Figures 1 and 2. Within the normal cytology group, women who were $\mathrm{HPV}^{+}$were significantly more anxious and distressed than women who were $\mathrm{HPV}^{-}$. Within the abnormal/unsatisfactory cytology group, testing positive for HPV was associated with a significantly higher CSQ scores but there were no differences between the two HPV groups in terms of state anxiety, with both HPV+ and HPV- women 
demonstrating elevated anxiety levels. Mean anxiety scores (pro-rated for comparison with the full length version of STAl, (see (25)) among the HPV + group with normal cytology (44, sd 15) and with abnormal/unsatisfactory cytology (46, sd 16) were raised well above the normative score (36, sd 11). Psychological distress (CSQ) scores among the $\mathrm{HPV}^{+}$group with normal cytology approximated those reported by Wardle et al (24) in women with abnormal cytology (borderline/ mild dyskaryosis mean 10, sd 3.2; CIN2/3 mean 13, sd 3.6). However, scores among $\mathrm{HPV}^{+}$women who had abnormal/unsatisfactory cytology were markedly higher. Because of the higher proportion of high grade lesions in the HPV + group, we repeated the analyses excluding women with CIN 2 or 3 . The same pattern of results was observed with higher anxiety and distress reported in the HPV+ group (STAl score 13, sd 5.0; CSQ score 16, sd 4.5).

- Insert Figures 1 and 2 about here -

We then examined women's feelings about their sexual relationships since HPV testing (see Table 3). Within the

\section{Page 1441 - - >}

normal cytology group, significantly more $\mathrm{HPV}^{+}$women reported feeling worse than usual about their sexual relationships than women who were $\mathrm{HPV}^{-}$. Similar findings were observed in women with abnormal/ unsatisfactory cytology who tested HPV+ compared with none of the HPV- women in this group.

- Insert Table 3 about here -

\section{Discussion}

This study shows that testing positive for HPV was associated with higher levels of anxiety and concern about sexual partners one week following screening. Women with normal cytology who were $\mathrm{HPV}^{+}$were significantly more anxious than those who were negative, on both the general anxiety measure (STAI) and the screening specific measure of psychological wellbeing (CSQ). Among women with abnormal or unsatisfactory cytology results, both anxiety and psychological distress scores were higher in the $\mathrm{HPV}^{+}$women, however, the difference reached significance only for the cervical screening specific measure of psychological distress (CSQ). Higher anxiety scores among $\mathrm{HPV}^{+}$women could be attributed in part to the smear result because the $\mathrm{HPV}+$ women included a higher proportion of high grade lesions. However, when women with high grade lesions were excluded from the analyses, the same pattern of findings was observed.

The study suggests that HPV testing may have an adverse psychosocial impact on women who test $\mathrm{HPV}^{+}$when it is used as a primary screening test alongside conventional cytology. Mean anxiety scores among the HPV ${ }^{+}$women with normal cytology were raised well above the normative score, consistent with other studies of women with abnormal cytology e.g. $(24 ; 26 ; 27)$.

Importantly, when we examined women's feelings towards their sexual partners, we found that $\mathrm{HPV}^{+}$women demonstrated significantly greater concerns about their sexual 
relationships than women who tested $\mathrm{HPV}^{-}$, irrespective of their cervical smear result. Among women with normal and abnormal or unsatisfactory cytology who were HPV ${ }^{+}$, approximately one third reported feeling worse about previous and future sexual partners, compared to between $0-2 \%$ of women who were HPV ${ }^{-}$. These findings are suggestive of a marked negative impact on feelings about sexual relationships among women who were $\mathrm{HPV}^{+}$, and are consistent with a lack of public awareness about the sexually transmitted aetiology of cervical abnormalities.

Previous research that has investigated responses to HPV infection (including both highrisk HPV types and visible genital warts) found that respondents with HPV demonstrated high levels of psychological and psychosexual dysfunction, equivalent to patients with other STIs such as Herpes Simplex Virus $(20 ; 28)$. It is important to note that both of these studies included a large proportion of patients with visible genital warts and may therefore over represent the negative psychosocial sequelae following a diagnosis of asymptomatic HPV infection. However, a further study measured hypothetical responses to testing HPV + for high-risk types in a sample of college students and found that women anticipated anger, fear, anxiety, regret, confusion and feeling dirty (29). Qualitative research has also identified concerns about trust and fidelity with sexual partners, in addition to anxiety, distress and worry about the stigma of testing positive for a sexually transmitted infection (18). The findings are contrary to those reported by Reed et al (30) who found no significant differences in psychosexual outcomes among women testing positive for high-risk HPV types. One explanation might be that Reed et al's study sample comprised women recruited for a study on vaginitis presenting either with symptoms or for a routine pelvic examination, and had a demanding 12 month follow-up protocol. As such, the sample may not be typical of women attending for routine cytological screening. Our findings suggest that the sexually transmitted nature of HPV may impose a psychosocial burden on women over and above the impact of an abnormal cytology result.

Consistent with previous research, this study demonstrated a short term adverse psychosocial impact of testing positive for HPV in the context of routine cervical screening, even among women with normal cytology $(20 ; 31 ; 32)$. It is an important finding since one of the major criticisms of HPV testing is its lack of specificity for detecting clinically significant disease, which could result in large numbers of women testing positive for transient HPV, many of whom would never have experienced any cytological abnormality (33;34). Abnormal cytology results in cervical screening are commonly associated with anxiety and this has been found to be alleviated by simple information interventions in some studies (35). However, a positive HPV result appears to have particular impact on feelings about sexual relationships and psychosexual wellbeing, and as such may have very different implications for the provision of information and advice for women participating in testing to help alleviate their concerns about infection. Psychosocial harms as well as clinical benefits need to be carefully evaluated in decisions to incorporate HPV testing into cervical screening. Despite a large body of clinical and economic data on HPV testing, research on psychosocial outcomes is lacking and has perhaps been somewhat overlooked to date $(36 ; 37)$.

Although these findings shed light on some aspects of the psychosocial impact of HPV testing, there are limitations to the research. In the current study HPV+ women with normal cytology were followed up with colposcopy within the clinical research protocol. 
This follow-up regimen may have enhanced the feelings of anxiety among this group (38), however, it would not be expected to influence feelings towards sexual partners. Examination of the psychosocial impact is needed according to different follow-up regimens for women who test positive. It is also important to note that the study

\section{Page $1442-->$}

only investigated the short term impact of HPV testing and further research is needed to investigate the medium and long term implications of testing. However, even a short term adverse psychosocial impact alone has implications for provision of information and support services, and clinician consultation times could be increased if large numbers of women experience high levels of distress following a positive test result.

The study included a comparatively well educated sample of white British women, due to the location of the well-woman clinic where it was carried out, and it is possible that the adverse psychosocial impact could be different in other groups. Research is now needed to evaluate the psychosocial impact of testing $\mathrm{HPV}^{+}$among women of varying socioeconomic position and ethnicity. Such research also needs to consider psychosocial benefits of HPV testing, as well as harms, since benefits such as reassurance may represent important outcomes of testing negative. Most urgently perhaps, research is needed to evaluate the impact among women with borderline smears (ASC-US) who in the US are faced with different management options (HPV tests or repeat cytology) following the recent revision of the Bethesda Guidelines.

Consideration of the psychosocial consequences of HPV testing is important. Millions of women participate in cervical screening programmes each year and may potentially be affected. The psychosocial impact of HPV testing is currently not well understood and needs further investigation before decisions are made about its introduction into national cervical screening programmes. 


\section{References}

(1) NHS cervical screening programme: celebrating 15 years of achievement. Patnick $\mathrm{J}$, editor. 2003. London, NHSCSP.

(2) Bosch FX, Lorincz A, Munoz N, Meijer CJ, Shah KV. The causal relation between human papillomavirus and cervical cancer. J Clin Pathol 2002; 55(4):244-265.

(3) Solomon D, Schiffman M, Tarone R. Comparison of three management strategies for patients with atypical squamous cells of undetermined significance: baseline results from a randomized trial. J Natl Cancer Inst 2001; 93(4):293-299.

(4) Kjaer SK, van den Brule AJ, Paull G, Svare El, Sherman ME, Thomsen BL et al. Type specific persistence of high risk human papillomavirus (HPV) as indicator of high grade cervical squamous intraepithelial lesions in young women: population based prospective follow up study. BMJ 2002; 325(7364):572.

(5) Sasieni P, Cuzick J. Could HPV testing become the sole primary cervical screening test? J Med Screen 2002; 9(2):49-51.

(6) Mandelblatt JS, Lawrence WF, Womack SM, Jacobson D, Yi B, Hwang YT et al. Benefits and costs of using HPV testing to screen for cervical cancer. JAMA 2002; 287(18):2372-2381.

(7) Wright TC, Jr., Cox JT, Massad LS, Twiggs LB, Wilkinson EJ. 2001 consensus guidelines for the management of women with cervical cytological abnormalities. JAMA 2002; 287(16):2120-2129.

(8) Cuzick PJ, Szarewski A, Cubie H, Hulman G, Kitchener H, Luesley D et al. Management of women who test positive for high-risk types of human papillomavirus: the HART study. Lancet 2003; 362(9399):1871-1876.

(9) Wright TC, Jr., Schiffman M, Solomon D, Cox JT, Garcia F, Goldie S et al. Interim guidance for the use of human papillomavirus DNA testing as an adjunct to cervical cytology for screening. Obstet Gynecol 2004; 103(2):304-309.

(10) Schiffman M, Adrianza ME. ASCUS-LSIL Triage Study. Design, methods and characteristics of trial participants. Acta Cytol 2000; 44(5):726-742.

(11) Little J. Effectiveness of testing for high risk HPV for triage of low grade abnormal smears is being assessed in TOMBOLA trial. BMJ 2001; 323:109.

(12) Wise J. UK pilot scheme for HPV testing announced. BMJ 2000; 320(7235):600.

(13) Wright TC, Jr., Cox JT, Massad LS, Twiggs LB, Wilkinson EJ. 2001 consensus guidelines for the management of women with cervical cytological abnormalities. JAMA 2002; 287(16):2120-2129.

(14) Solomon D, Schiffman M, Tarone R. Comparison of three management strategies for patients with atypical squamous cells of undetermined significance: baseline results from a randomized trial. J Natl Cancer Inst 2001; 93(4):293-299. 
(15) Woodman CB, Collins S, Winter H, Bailey A, Ellis J, Prior P et al. Natural history of cervical human papillomavirus infection in young women: a longitudinal cohort study. Lancet 2001; 357(9271):1831-1836.

(16) Miller AB. Natural history of cervical human papillomavirus infections. Lancet 2001; 357(9271):1816.

(17) Ramirez JE, Ramos DM, Clayton L, Kanowitz S, Moscicki AB. Genital human papillomavirus infections: knowledge, perception of risk, and actual risk in a nonclinic population of young women. J Womens Health 1997; 6(1):113-121.

(18) McCaffery KJ, Forrest S, Waller J, Desai M, Szarewski A, Wardle J. Attitudes towards HPV testing: a qualitative study of beliefs among Indian, Pakistani, African Caribbean and white British women in the UK. Br J Cancer 2003; 88:42-46.

(19) Waller J, McCaffery KJ, Forrest S, Wardle J. Human papillomavirus (HPV) and cervical cancer: issues for biobehavioral and psychosocial research. Annals of Behavioral Medicine 2004; 27(1):68-79.

(20) Conaglen HM, Hughes R, Conaglen JV, Morgan J. A prospective study of the psychological impact on patients of first diagnosis of human papillomavirus. International Journal of Std \& Aids 2001; 12(10):651-658.

(21) Stewart-Brown S, Farmer A. Screening could seriously damage your health. BMJ 1997; 314(7080):533-534.

(22) Waller J, McCaffery KJ, Forrest S, Szarewski A, Cadman L, Wardle J. Awareness of human papillomavirus (HPV) among women attending a well woman clinic. Sex Transm Infect 2003; 79:320-322.

(23) Marteau TM, Bekker $\mathrm{H}$. The development of a six-item short-form of the state scale of the Spielberger State-Trait Anxiety Inventory (STAI). Br J Clin Psychol 1992; 31 ( Pt 3):301-306.

(24) Wardle J, Pernet AL, Stephens D. Psychological consequences of positive results in cervical cancer screening. Psychology and Health 1995; 10:185-194.

(25) Marteau TM, Bekker $\mathrm{H}$. The development of a six-item short-form of the state scale of the Spielberger State-Trait Anxiety Inventory (STAI). Br J Clin Psychol 1992; 31 ( Pt 3):301-306.

(26) Howells RE, Dunn PD, Isasi T, Chenoy R, Calvert E, Jones PW et al. Is the provision of information leaflets before colposcopy beneficial? A prospective randomised study. Br J Obstet Gynaecol 1999; 106(6):528-534.

(27) Richardson PH, Doherty I, Wolfe CDA, Carman N, Chamberlain F, Holtom R et al. Evaluation of cognitive-behavioural counselling for the distress associated with an abnormal cervical smear result. Br J Health Psychol 1996; 1:327-338. 
(28) Clarke P, Ebel C, Catotti DN, Stewart S. The psychosocial impact of human papillomavirus infection: implications for health care providers. Int J STD AIDS 1996; 7(3):197-200.

(29) Ramirez JE, Ramos DM, Clayton L, Kanowitz S, Moscicki AB. Genital human papillomavirus infections: knowledge, perception of risk, and actual risk in a nonclinic population of young women. J Womens Health 1997; 6(1):113-121.

(30) Reed BD, Ruffin MT, Gorenflo DW, Zazove P. The psychosexual impact of human papillomavirus cervical infections. J Fam Pract 1999; 48(2):110-116.

(31) Ramirez JE, Ramos DM, Clayton L, Kanowitz S, Moscicki AB. Genital human papillomavirus infections: knowledge, perception of risk, and actual risk in a nonclinic population of young women. J Womens Health 1997; 6(1):113-121.

(32) Clarke P, Ebel C, Catotti DN, Stewart S. The psychosocial impact of human papillomavirus infection: implications for health care providers. Int J STD AIDS 1996; 7(3):197-200.

(33) Woodman CB, Collins S, Winter H, Bailey A, Ellis J, Prior P et al. Natural history of cervical human papillomavirus infection in young women: a longitudinal cohort study. Lancet 2001; 357(9271):1831-1836.

(34) Miller AB. Natural history of cervical human papillomavirus infections. Lancet 2001; 357(9271):1816.

(35) Wilkinson C, Jones JM, McBride J. Anxiety caused by abnormal result of cervical smear test: a controlled trial. BMJ 1990; 300(6722):440.

(36) Wright TC, Jr., Cox JT, Massad LS, Twiggs LB, Wilkinson EJ. 2001 consensus guidelines for the management of women with cervical cytological abnormalities. JAMA 2002; 287(16):2120-2129.

(37) McCaffery KJ, Waller J, Forrest S, Wardle J. Testing for human papillomavirus in women with abnormal Pap smear results. JAMA 2002; 288(11):1350-1352.

(38) Marteau TM, Walker P, Giles J, Smail M. Anxieties in women undergoing colposcopy. Br J Obstet Gynaecol 1990; 97(9):859-861. 
Table 1. Participant characteristics

\begin{tabular}{|c|c|c|}
\hline Variable & $\mathrm{N}$ & $\%$ \\
\hline \multicolumn{3}{|l|}{ Age } \\
\hline$<30$ years & 150 & $(55)$ \\
\hline $30-34$ & 48 & $(18)$ \\
\hline $35-39$ & 26 & $(10)$ \\
\hline $40+$ & 47 & (17) \\
\hline \multicolumn{3}{|l|}{ Marital Status } \\
\hline Married/ living with partner & 138 & $(54)$ \\
\hline Single & 108 & $(42)$ \\
\hline Divorced/separated & 10 & $(4)$ \\
\hline \multicolumn{3}{|l|}{ Ethnic group } \\
\hline White & 224 & $(90)$ \\
\hline Black & 4 & (2) \\
\hline Asian & 7 & (3) \\
\hline Other & 14 & (6) \\
\hline \multicolumn{3}{|l|}{ Age left full time education } \\
\hline Under 16 years & 20 & (8) \\
\hline $17-18$ years & 37 & (14) \\
\hline $19+$ years & 198 & $(78)$ \\
\hline \multicolumn{3}{|l|}{ Smoking status } \\
\hline Yes & 82 & $(32)$ \\
\hline No & 174 & $(68)$ \\
\hline \multicolumn{3}{|c|}{ No. of sexual partners in last 12 months } \\
\hline 0 & 8 & (3) \\
\hline 1 & 172 & (67) \\
\hline 2 & 51 & $(20)$ \\
\hline 3 & 12 & (5) \\
\hline $4+$ & 15 & (6) \\
\hline
\end{tabular}


Table 2. Participant cytology and HPV test results

\begin{tabular}{l|l|l}
\hline Variable & N & $\%$ \\
\hline HPV status & & \\
HPV positive & 69 & $(25)$ \\
HPV negative & 202 & $(75)$ \\
& & \\
\hline Cytology & & \\
Normal & 231 & $(85)$ \\
Unsatisfactory & 16 & $(6)$ \\
Borderline & 11 & $(4)$ \\
CIN1 & 5 & $(2)$ \\
CIN2 & 7 & $(3)$ \\
CIN3 & 1 & $(0)$ \\
& & \\
Cervical smear and HPV test groups & & \\
Normal smear, HPV negative & 185 & $(68)$ \\
Normal smear, HPV positive & 46 & $(17)$ \\
Abnormal/unsatisfactory smear, HPV negative & 17 & $(6)$ \\
Abnormal/unsatisfactory smear, HPV positive & 23 & $(8)$ \\
& & \\
\hline
\end{tabular}


Table 3. Feelings towards sexual partners

\begin{tabular}{|c|c|c|c|c|c|c|}
\hline & \multicolumn{3}{|c|}{ Normal cytology } & \multicolumn{3}{|c|}{ Abnormal/unsatisfactory cytology } \\
\hline & $\begin{array}{l}\mathrm{HPV}^{-} \\
\mathrm{n}(\%)\end{array}$ & $\begin{array}{c}\mathrm{HPV}^{+} \\
\mathrm{n}(\%)\end{array}$ & Sig & $\begin{array}{l}\mathrm{HPV}^{-} \\
\mathrm{n}(\%)\end{array}$ & $\begin{array}{c}\mathrm{HPV}^{+} \\
\mathrm{n}(\%)\end{array}$ & Sig \\
\hline $\begin{array}{r}\text { Feelings about current partner } \\
\text { Worse/ much worse than usual } \\
\text { Better/same as usual }\end{array}$ & $\begin{array}{c}160(1) \\
2(99)\end{array}$ & $\begin{array}{c}3(8) \\
33(92)\end{array}$ & $\mathrm{p}=.04$ & $\begin{array}{c}0(0) \\
16(100)\end{array}$ & $\begin{array}{c}2(13) \\
14(87)\end{array}$ & ns \\
\hline $\begin{array}{r}\text { Feelings about previous partners } \\
\text { Worse/much worse than usual } \\
\text { Better/same as usual }\end{array}$ & $\begin{array}{c}167(1) \\
2(99)\end{array}$ & $\begin{array}{l}15(33) \\
30(67)\end{array}$ & $\mathrm{p}<.0001$ & $\begin{array}{c}0(0) \\
15(100)\end{array}$ & $\begin{array}{c}8(35) \\
15(65)\end{array}$ & $\mathrm{p}=.01$ \\
\hline $\begin{array}{l}\text { Feelings about future partners } \\
\text { Worse/much worse than usual } \\
\text { Better or same as usual }\end{array}$ & $\begin{array}{c}3(2) \\
173(98)\end{array}$ & $\begin{array}{l}12(27) \\
32(73)\end{array}$ & $\mathrm{p}<0001$ & $\begin{array}{c}0(0) \\
15(100)\end{array}$ & $\begin{array}{c}7(32) \\
15(68)\end{array}$ & $\mathrm{p}=.02$ \\
\hline
\end{tabular}


Figure 1. Mean STAI scores

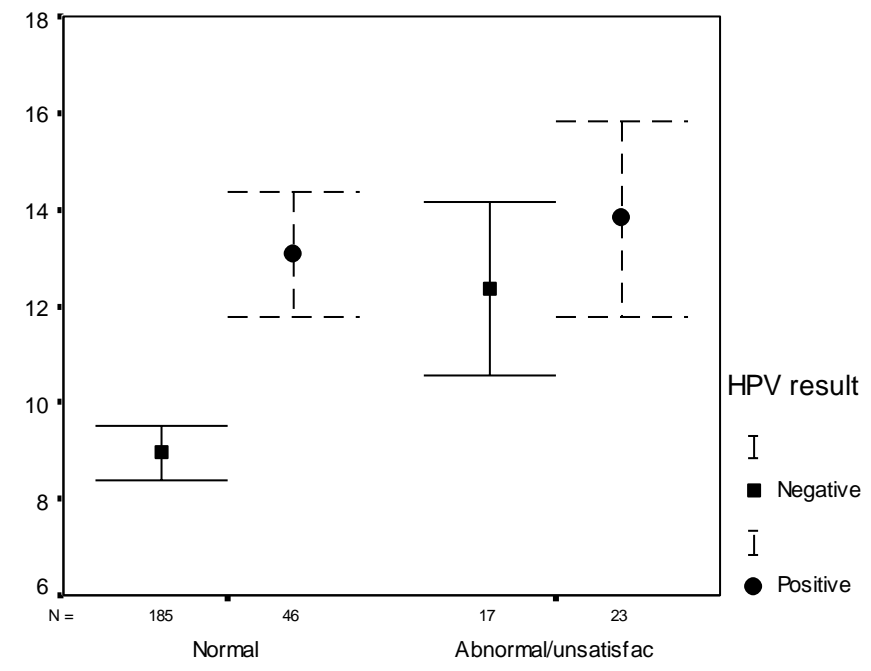

Smear result
Figure 2. Mean CSQ scores

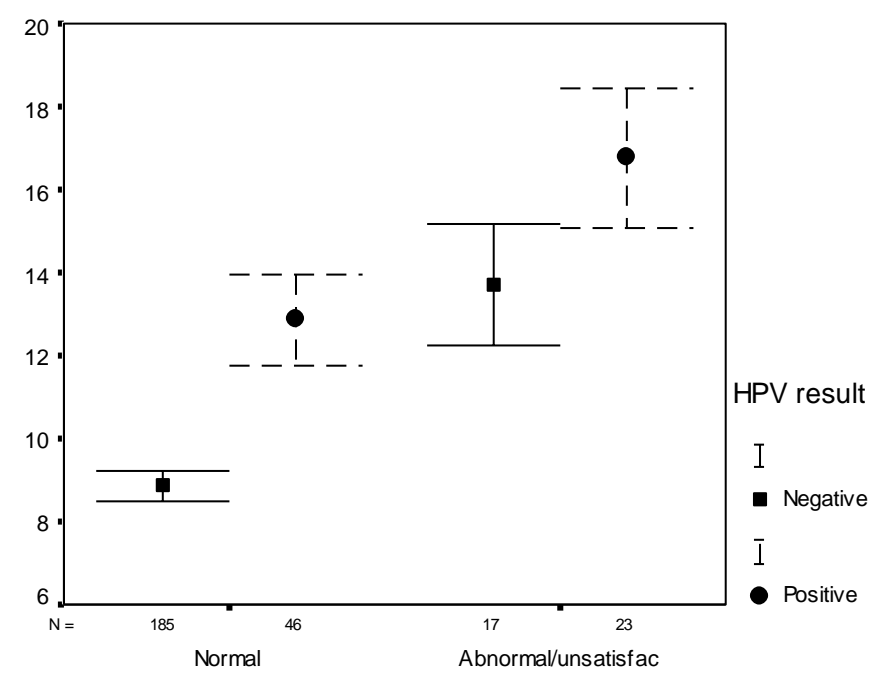

Smear result 
Fig 1. Legend

\begin{tabular}{|c|c|c|c|}
\hline \multicolumn{2}{|l|}{$\begin{array}{l}\text { Smear normal } \mathrm{HPV}^{+} \text {vs. HPV } \\
\text { STAI } \\
\text { CSQ } \\
\text { CSQ }\end{array}$} & \multicolumn{2}{|l|}{$\begin{array}{ll}\text { STAI } & F(1,267)=1.3 \text { (n.s.) } \\
\text { CSQ } & F(1,267)=8.8, p=.002\end{array}$} \\
\hline \multicolumn{2}{|c|}{$\begin{array}{l}\text { HPV positive Smear normal vs. smear abnormal/unsatifac } \\
\text { STAI } F(1.267)=0.55 \text { (n.s.) } \\
\text { CSQ } \quad F(1,267)=15, p=.0001\end{array}$} & \multicolumn{2}{|c|}{$\begin{array}{l}\text { HPV negative smear normal vs. smear abnormal/unsatisfac } \\
\text { STAI } F(1,267)=11, p=.0008 \\
\text { CSQ } F(1,267)=21, p<.0001\end{array}$} \\
\hline \multicolumn{2}{|l|}{ Mean STAI scores $(95 \%$ CI $)$} & \multicolumn{2}{|l|}{ Mean CSQ scores $(95 \%$ CI) } \\
\hline Smear normal/HPV ${ }^{-}$ & $9.0(8.4-9.5)$ & Smear normal/HPV ${ }^{-}$ & $8.9(8.4-9.3)$ \\
\hline Smear normal $\mathrm{HPV}^{+}$ & $13(12-14)$ & Smear normal $\mathrm{HPV}^{+}$ & $13(12-14)$ \\
\hline Smear abnormal/unsatisfactory $\mathrm{HPV}^{-}$ & $12(10-14)$ & Smear abnormal/unsatisfactory $\mathrm{HPV}^{-}$ & $14(12-15)$ \\
\hline Smear abnormal/unsatisfactory $\mathrm{HPV}^{+}$ & $14(12-15)$ & Smear abnormal/unsatisfactory $\mathrm{HPV}^{+}$ & $17(16-18)$ \\
\hline
\end{tabular}




\section{Acknowledgements}

We would like to thank staff and patients at the Margaret Pyke clinic, London for their contribution to the study. Support from Cancer Research UK (formerly the Imperial Cancer Research Fund) is gratefully received.

$\mathrm{KM}$ wrote the paper, carried out the analyses and participated in the study design. JoW was involved in writing the paper and the statistical analysis. SF and LC were involved in the data collection and commented on drafts of the paper. AS and JW conceived the study and commented on the statistical analysis and writing of the paper. $\mathrm{KM}$ is the guarantor.

There are no competing interests. 